\title{
Flame stability and behavior inside meso-scale combustor with different flame holder
}

\author{
Lilis Yuliati ${ }^{1, *}$ \\ ${ }^{1}$ Mechanical Engineering Department, Brawijaya University, Indonesia
}

\begin{abstract}
Flame stability and behavior inside meso-scale combustor with different flame holder was investigated experimentally. Three types of flame holder i.e. wire mesh, flat plate with circular holes and flat plate with narrow slits, were used to improve the flame stability inside the meso-scale combustor. Combustor with flat plate - narrow slits flame holder has the best flame stability, i.e. stable flame established inside the combustor at the highest reactant velocity compared to the other combustor with the different flame holder. Furthermore, combustor with wire mesh and flat plate with narrow slits have a relatively uniform flame colour at the combustor cross section, compared to flame visualization inside mesoscale combustor with flame holder of flat plate with circular holes. This phenomena is related to non-uniform reactant distribution on the combustor cross section.
\end{abstract}

\section{Introduction}

The development of micro-power generator (MPG) promotes many researchers about micro- and meso-scale combustor as a main component of the micro-power generator [1-2]. Micro- and meso-scale combustor with a stable combustion is an important component required in MPG systems. However, it is well understood that maintained stable flame inside meso- or micro-scale combustor are difficult, related to short fuel residence time as well as high heat loss to heat generation ratio due to high surface to volume ratio. Especially, it is difficult to obtain stable flame at a high reactant velocity due to shorter fuel residence time, resulting the flame instability such as blow-off. It is important to stabilize the flame at a high reactant velocity to obtain high power density MPG.

Many researches were conducted to improve flame stability inside micro- and mesoscale combustor, such as using backward facing step [3,4], wire mesh [5,6], as well as using plate flame holder [7]. Backward facing step has an important role to stabilize the flame inside micro combustor by prolong fuel residence time in the combustor and improving the fuel mixing in the presence of vortex near the step. Wire mesh has a purpose as flame holder and improves heat recirculation from the flame to the unburned reactant through heat conduction on the combustor wall. As the results, flame stability increased. For the same combustor and reactant, combustor with wire mesh flame holder has more stable combustion than combustor with backward facing step. This is inferred due to wider

\footnotetext{
* Corresponding author: lilis_y@ub.ac.id
} 
contact area between flame holder - reactant which results better heat recirculation from the flame to the unburned reactant. Therefore, this is important to understand the role of the flame holder type on the heat recirculation, flame stability and behavior in meso-scale combustor.

This research was intended to understand flame stabilization mechanism and flame behavior, such as flame temperature and visualization, related to heat recirculation from the flame to the unburned reactant. In this research, heat recirculation will be optimized by geometry and thermal conductivity of the flame holder. The aim of the research is to obtain meso-scale combustor which has stable combustion at high reactant velocity.

\section{Experimental setup}

Figure 1 shows a schematic of meso-scale combustor used in this research. The combustor was made from quartz glass tube with an inner diameter of $3.5 \mathrm{~mm}$ and an outer diameter of $4.9 \mathrm{~mm}$. It is consisting of two pieces of glass tube with length of 20 and $10 \mathrm{~mm}$, connected with a heat resistant ceramic adhesive (Ceramabond 569, Aremco Products Inc.). Three type flame holders i.e. wire mesh, flat plate with circular holes and flat plate with narrow slits, were used in this research. The wire mesh was made from stainless steel, while the flat plate flame holders were made from copper. For further discussion the wire mesh, flat plate with circular holes and flat plate with narrow slits were named as type-I flame holder, type-II flame holder and type-III flame holder respectively. Detail geometry of each flame holder is indicated in Fig.2. Each piece of these flame holders was inserted between the quartz glass tubes to build the combustors.

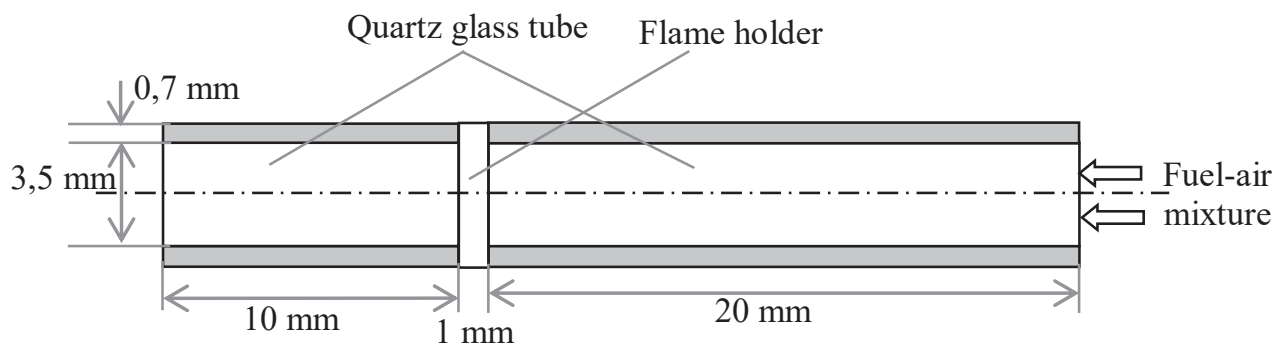

Fig. 1. Schematif of meso-scale combustor.
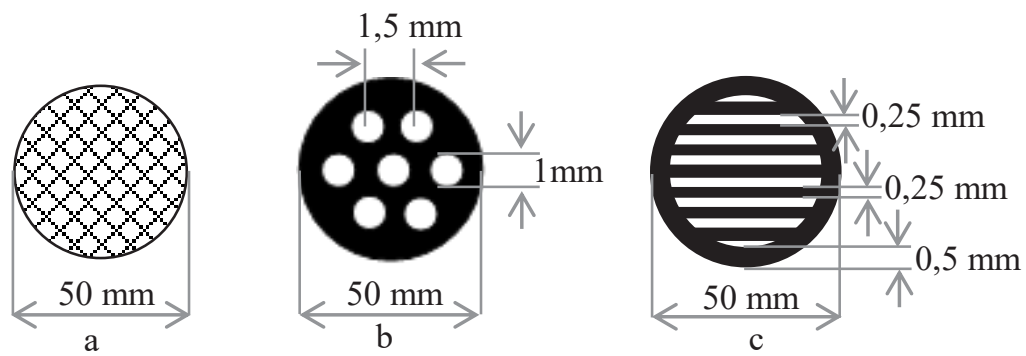

Fig. 2. Detail of a. type-I flame holder, b. type-II flame holder, c. type-III flame holder.

Butane was used as fuel and ambient air was used as the oxidizer, supplied to the combustor from the compressor tank. Fuel and air flow rate were adjusted using flow meter (Koflock, R1250) with measurement range of $2-20 \mathrm{~mL} /$ minute and $50-500 \mathrm{~mL} /$ minute 
respectively. Fuel and air were mixed in mixing chamber before introducing into the combustion chamber. Fuel-air mixture was introduced into the combustor at different flow rate and equivalence ratio to check the flame stability. The mixture was ignited at the end of the combustor using a torch. Flame propagates into the combustor and stabilized near the flame holder at the suitable fuel and air flow rate.

Flame stability is investigated by operating the meso-scale combustor at a constant fuel flow rate, then air flow rate is increased or decreased gradually until flame quenching or blow-off occurred. Furthermore, the same procedure is carried out by varying the fuel flow rate, until it reaches its minimum and maximum value where the flame is stable inside the combustor near the flame holder. Flame visualization is taken from the front and the side of the combustor using a Canon 600D cameras. Flame temperature measurements are conducted on the combustor axis at a certain axial position where the flame temperature achieves the maximum value. Measurement of exhaust gas temperature was conducted at the combustor axis at the end of combustor, $10 \mathrm{~mm}$ downstream of the flame holder. The temperature is measured using an R-type thermocouple with a diameter of $0.2 \mathrm{~mm}$ connected with data logger (Advantec).

\section{Results and discussions}

The flame could be stabilized in three combustors with different flame holder. The flame has blue luminosity. Stable flame in this study is combustion with a fixed flame located inside the combustor near the flame holder. Figure 3 indicates an area of flame stabilization limit inside combustors with different flame holder. The region is delineated in the plane of $\mathrm{V}-\phi$ (velocity of reactant - equivalence ratio).

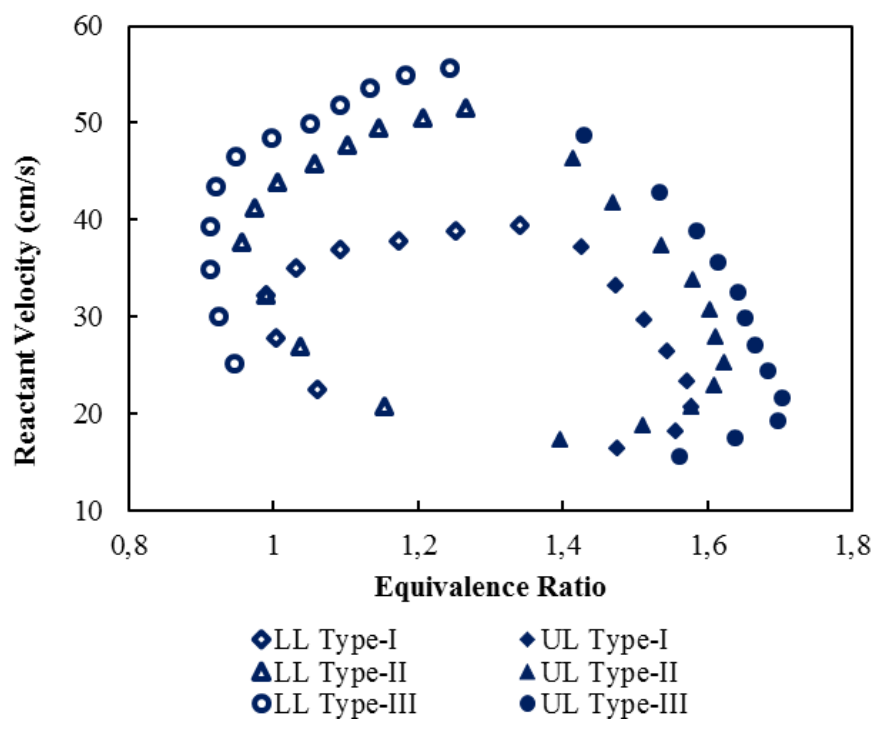

Fig. 3. Flame stabilization limit area in meso-scale combustor with different flame holder.

The figure denotes that meso-scale combustor using type-III flame holder has the most stable combustion. This is indicated by the widest area of flame stability limit on the V- $\phi$ plane. Flame could be stabilized in this combustor type for leaner or richer mixture, as well as for higher reactant velocity. Vice versa, the meso-scale combustor using type-I flame holder has the narrowest flame stability area and lower reactant velocity in which flame 
could be stabilized in the combustor. Flame holder has an important role to realize a stable flame within the meso-scale combustor.

Flame stability can be achieved if the reactant velocity could be balanced by flame propagation speed. From this fact could be concluded that the meso-scale combustor using type-III flame holder has the highest flame propagation speed if compared to the other combustor types. The flame propagation speed is affected significantly by flame and reactant temperature. The higher reactant and flame temperature conduce the increasing of flame propagation speed. From these explanations could be expected that the highest flame temperature occurred in meso-scale combustor using type-III flame holder. Moreover, it could be supposed that the reactant temperature entering the combustor with type-III flame holder is higher. This fact will be shown at the next section about flame temperature measurement. Flame visualization inside meso-scale combustor with different flame holder at various reactant velocity and constant equivalence ratio is indicated in Table 1.

Table 1. Flame visualization in meso-scale combustor with different flame holder at constant equivalence ratio.

\begin{tabular}{|c|c|c|c|}
\hline Condition & $\begin{array}{c}\text { Type-I } \\
\text { flame holder }\end{array}$ & $\begin{array}{c}\text { Type-II } \\
\text { flame holder }\end{array}$ & $\begin{array}{c}\text { Type-III } \\
\text { flame holder }\end{array}$ \\
\hline $\begin{array}{c}\phi=1.3 \\
\mathrm{~V}=20 \mathrm{~cm} / \mathrm{s}\end{array}$ & & & \\
\hline $\begin{array}{c}\phi=1.3 \\
\mathrm{~V}=37.5 \mathrm{~cm} / \mathrm{s}\end{array}$ & & & \\
\hline $\begin{array}{c}\phi=1.3 \\
\mathrm{~V}=50 \mathrm{~cm} / \mathrm{s}\end{array}$ & & & \\
\hline
\end{tabular}

The table above shows that the flame does not fulfil the combustor cross section. There is a gap between the flame and the combustor wall. Flame visualizations at the Table 1 show that flame inside combustor with type-I flame holder has the wider flame cross section compared to the other flame holder type. Furthermore, flame visualization shows that combustor with type-I and type-III flame holder have relatively uniform flame colour. Vice versa, non-uniform flame colour occurs in combustor with type-II flame holder, due to uneven reactants distribution on the combustor cross section. This phenomena relates to the shape of holes or gaps in the flame holder that determines the distribution of the reactants when entering the combustion zone, which further determines the flame shape. Brighter flame colour denotes more intense combustion reaction zone due to high concentration reactant.

Table 1 indicates flame visualization in meso-scale combustors with three types flame holder, at constant equivalence ratio and various reactant velocities. Flames luminosity becomes brighter with the increasing of reactant velocity. Likewise, its cross section becomes wider by reactant velocity. As the amount of reactants increases, the volumetric heat release increase, resulting in larger combustion temperatures. It could suppress the flame quenching near the combustor wall due to heat loss as well as radical quenching. Figure 4 indicates flame and exhaust gas temperature in meso-scale combustor with various flame holder types. 


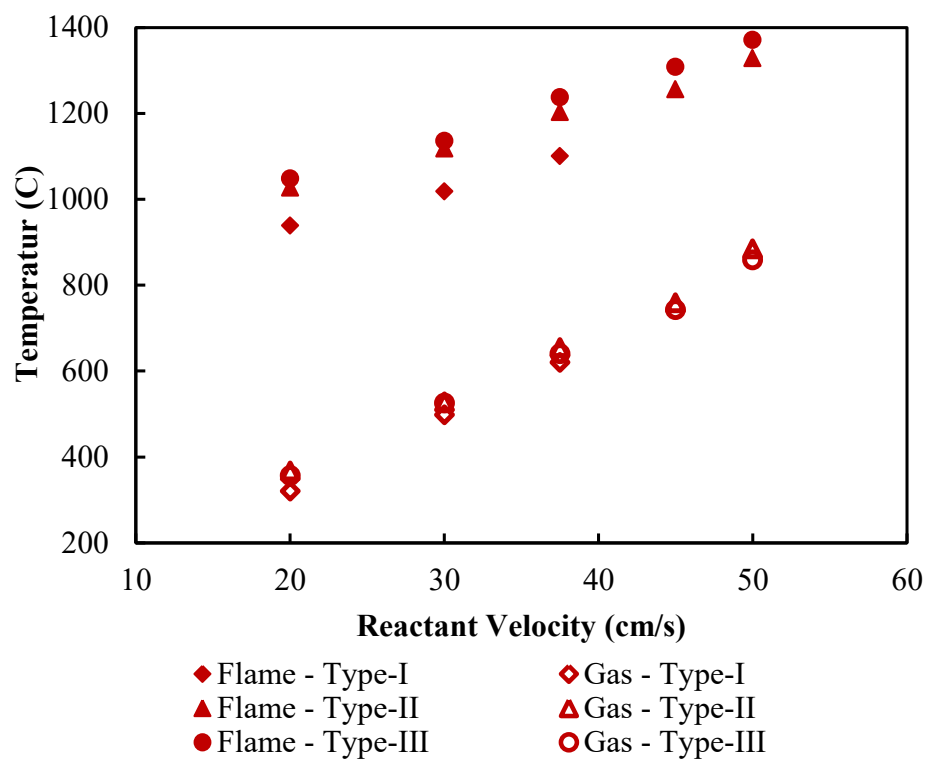

Fig. 4. Flame and exhaust gas temperature in meso-scale combustor with different flame holder.

The figure shows that as the reactant velocity increases, the flame and exhaust gas temperature in each combustor with different flame holder will increase. However, we can see that exhaust gas temperature of all combustors with different flame holder type are relatively same, while the flame temperature on the combustors are significantly different. Especially combustor with type-I flame holder has the lowest flame temperature. This phenomena can be explained as follows. Except to holding the flame, flame holder is also assist heat recirculation from the flame to the reactant. There are two methods of heat transfer from the flame to unburned cold reactant, i.e. direct heat transfer from the flame to unburned reactant by radiation and indirect heat transfer from the flame to unburned reactant through heat conduction on the combustor wall. However, the direct heat transfer is very small and could be neglected due to low radiation of the blue flame. Hence the important heat recirculation mechanism is conduction heat transfer through combustor wall. Heat from the combustor wall is convected to the unburned reactant. Heat convection from the combustor wall to the unburned reactant is affected significantly by the flame holder, its material as well as geometry of flame holder.

Heat flow from the flame to unburned reactant is as follows. A part of heat generated from the combustion process is convected to the combustor wall $(\mathrm{H})$. A fraction of the convected heat will lose to the environment $\left(\mathrm{H}_{\mathrm{L}}\right)$ and the remainder will be conducted to the upstream direction $\left(\mathrm{Q}_{\mathrm{R}}\right)$. It can be denoted as $\mathrm{H}=\mathrm{H}_{\mathrm{L}}+\mathrm{Q}_{\mathrm{R}}$. $\mathrm{Q}_{\mathrm{R}}$ is conducted to the upstream direction through the flame holder, hence a part of the $Q_{R}$ is conducted to the flame holder $\left(\mathrm{Q}_{\mathrm{RF}}\right)$ and subsequently convected to the reactant which flows through the small gaps in the flame holder. The remainder is conducted to the upstream direction $\left(\mathrm{Q}_{\mathrm{RW}}\right)$ and eventually convected to unburned reactant. The amount of heat conduction is $Q_{R}=Q_{R F}+Q_{R W} Q_{R}$ is an important factor which represent the quantity of heat recirculation from the flame to the unburned reactant. The fraction of $\mathrm{Q}_{\mathrm{RF}}$ is larger compared to $\mathrm{Q}_{\mathrm{RW}}$ due to the high thermal conductivity of flame holder which made from copper or stainless steel than the thermal conductivity of the combustor wall. Therefore, heat recirculation to unburned reactant through the flame holder becomes much important than the other one through the upstream combustor wall. 
Heat recirculation to the reactant through the flame holder by heat convection is greatly influenced by thermal conductivity of flame holder and contact area between reactant flame holder surface. So that the geometry and material of flame holder become an important factor in the heat recirculation process and flame stabilization mechanism. TypeIII flame holder was made from copper which has high thermal conductivity and it has wider contact area between reactant - flame holder surface. This condition generates the most effective heat transfer to the unburned reactant. This results more heat loss by convection from the flame to the combustor wall, so that the flame cross section becomes narrower. However, Type-III flame holder results more heat recirculation from the flame to the reactant and more reactant pre-heating to produce higher reactant temperature. These conditions promote higher burning velocity and more stable combustion. The higher heat loss from the flame to the combustor wall is the reason why the exhaust gas has almost same temperature, even though the flame temperature in each combustor were significantly different.

\section{Conclusions}

This study experimentally investigated flame stability and its behavior in meso-scale combustor affected by flame holder geometry. Conclusions of the experiment results are as follow, flame holder geometry affects heat recirculation and preheating of reactants in meso-scale combustor. It results the order of combustion stability from the most stable to less stable are combustion in combustor with type-III flame holder, type-II flame holder and type-I flame holder respectively. Flame visualization indicates a non-uniform flame color due to uneven reactant distribution at the combustor cross section in combustor with type-II flame holder. The last one, combustor with type-III flame holder generates the most effective heat recirculation from the flame to the unburned reactant. This is indicated by higher flame temperature while the exhaust gases temperature is almost same compared to the other combustor.

\section{References}

1. Fernandez-Pello, Proc. Combustion Ins. J, 29, 883-899 (2002).

2. Y. Ju, K. Maruta, Progress in Energy and Combustion Science J, 37, 669-715 (2011).

3. W.M. Yang, S.K. Chou, C. Shu, Z.W. Li, H. Xue, Applied Thermal Eng. J, 22 (2002) 1777-1787 (2002).

4. M. Baigmohammadi, S. Tabejamaat, Y. Farsiani, Chem. Eng. and Processing J, 95, 105-123 (2015).

5. L. Yuliati, T. Seo, M. Mikami, Comb. and Flame J, 159, 462-464 (2012).

6. M. Mikami, Y. Maeda, K. Matsui, T. Seo, L. Yuliati, Proc. Combustion Ins. J, 34, $3387-3394$ (2013).

7. J. Wan, A. Fan, Energy Conv. \& Management J, 101, 552-560 (2015). 